\title{
NA LUTA PELA GARANTIA DO DIREITO À EDUCAÇÃO: REFLEXÕES SOBRE A FORMAÇÃO DE PROFESSORES PARA A EDUCAÇÃO INFANTIL
}

\author{
In the combat for the ensure of the right to education: reflections on teacher training for \\ childhood education
}

\section{En la lucha por la garantía del derecho a la educación: reflexiones sobre la formación de los profesores para la educación infantil}

\author{
Valdete Côco* \\ Valéria Menassa Zucolotto ** \\ Renata Rocha Grola Lovatti ${ }^{* * *}$ \\ Kallyne Kafuri Alves**** \\ Verônica Belfi Roncetti Paulino*****
}

\begin{abstract}
Resumo
Integrando a luta pela ampliação do direito à educação, a Educação Infantil (EI) vem ganhando afirmação social, evidenciando demandas por ampliar a oferta e, simultaneamente, qualificar o atendimento. Com isso, destacam-se discussões referentes a sua função pedagógica, abarcando a docência e os processos formativos. Nesse contexto, circunscrevendo as políticas públicas de formação, este artigo decorre de pesquisa desenvolvida a partir da implementação da especialização em docência, acompanhando uma turma de 36 professoras atuantes na EI. Com referenciais teórico-metodológicos bakhtinianos, por meio de abordagem qualitativa exploratória, focaliza as trajetórias de formação com procedimentos de produção de memoriais, de aplicação de questionário e de mobilização de grupo focal. $\mathrm{Na}$ atenção às relações dialógicas que constituem as vivências na EI, apresenta três eixos de análises, referentes ao trabalho docente, as motivações para a atuação e as proposições de práticas pedagógicas. Como síntese, assinala a emergência de uma dialogia (intensa e, por vezes, tensa) que, integrando variados interlocutores, insta a discussão sobre a identidade da EI e, consequentemente, sobre a constituição da docência nesse campo, no bojo dos desafios que movem a luta pela garantia do direito à educação.
\end{abstract}

\footnotetext{
* Doutora em Educação pela Universidade Federal Fluminense; professora do Programa de Pós-Graduação em Educação do Centro de Educação da Universidade Federal do Espírito Santo (PPGE/CE/Ufes); coordenadora do Grupo de Pesquisa "Formação e Atuação de Educadores" (Grufae/Ufes). E-mail: valdetecoco@ hotmail.com

** Mestra em Educação pelo PPGE/CE/Ufes; pedagoga vinculada à Secretaria de Estado da Educação do Espírito Santo (Sedu); egressa do GRUFAE/Ufes. E-mail: valeriazucolotto@gmail.com
}

Mestra em Educação pelo PPGE/CE/UFES; professora vinculada à Secretaria Municipal de Cachoeiro de Itapemirim/ES; membro do Colegiado do Fórum Estadual de Educação Infantil/ES (Fopeies); integrante do Grufae/Ufes. E-mail: renatalovatti@hotmail.com.br

**** Doutoranda em Educação pela Universidade Federal do Espírito Santo (PPGE/CE/UFES); mestre em Educação pelo PPGE/CE/Ufes; integrante do GRUFAE/Ufes. E-mail: kallynekafuri@ hotmail.com

Doutoranda em Educação pelo PPGE/FEUSP; mestra em Educação PPGE/CE/Ufes; integrante do GEPSI/FEUSP; egressa do GRUFAE/Ufes. E-mail: veronicabroncetti@usp.gov.br 
PALAVRAS-CHAVE: Educação Infantil. Formação de professores. Trabalho docente.

\begin{abstract}
Integrating the struggle for the expansion of the right to education, childhood education has been gaining social affirmation, evidencing demands for expanding the offer and at the same time qualifying the attention. With this, we highlight discussions regarding their pedagogical role, covering teaching and training process. In this context, contain public training policies, this article is derived from a research developed from the implementation of specialization in teaching, accompanying a class of 36 teachers acting in the IE. With Bakhtinian theoretical-methodological references, through an exploratory qualitative approach, the training trajectories were focused with procedures of memory production, questionnaire application and focal group mobilization. In the attention to the dialogical relations that constitute the experiences in the childhood education, presents three axes of analysis, referring to the development of the teaching work, the motivations for the action and the propositions of pedagogical practices with the children. In syntheses, the emergence of a dialogue (intense and sometimes tense) that, integrating various interlocutors, points to the discussion on the identity of the childhood education and, consequently, on the constitution of teaching in that field, in the breast of the challenges that move the fight for the lien of the right to education.
\end{abstract}

KEYWORDS: Childhood Education. Teacher Training. Teaching Work.

\title{
Resumen
}

Integrando lo combat por la ampliación del derecho a la educación, la Educación Infantil (EI) viene ganando afirmación social, evidenciando las demandas por ampliar la oferta y simultáneamente calificar la atención. Con ello, se destacan discusiones referentes a su función pedagógica, abarcando la docencia y los procesos formativos. En este contexto, circunscribiendo las políticas públicas de formación, este artículo se deriva de una investigación desarrollada a partir de la implementación de la especialización en docencia, acompañando a una clase de 36 profesoras actuantes en la EI. Con referenciales teóricometodológicos bakhtinianos, por medio de abordaje cualitativo exploratorio, se enfocaron las trayectorias de formación con procedimientos de producción de memorias, de aplicación de cuestionario y de movilización de grupo focal. En la atención a las relaciones dialógicas que constituyen las vivencias en la EI, presenta tres ejes de análisis, referentes al desarrollo del trabajo docente, las motivaciones para la actuación y las proposiciones de prácticas pedagógicas con los niños. Como síntesis, se señala la emergencia de una dialoga (intensa y, a veces, tensa) que, integrando variados interlocutores, insta a la discusión sobre la identidad de la EI y, consecuentemente, sobre la constitución de la docencia en ese campo, en el seno de los desafíos que mueven la lucha por la garantía del derecho a la educación.

PALABRAS CLAVE: Educación Infantil. Formación de Profesores. Trabajo Docente.

\section{INTRODUÇÃO}

A luta pela ampliação do direito à educação mobiliza cobranças à responsabilização do Estado por investimentos no sistema de ensino, em especial, com vistas à garantia da oferta educacional nos termos das bases legais em vigência (BRASIL, 1996). Nessa mobilização, a Educação Infantil (EI) vem ganhando reconhecimento social, no horizonte da demanda por universalizar o atendimento para a pré-escola e ampliá-lo para a faixa da creche, conforme o Plano Nacional de Educação (BRASIL, 2014). Destacamos essas referências na continuidade da luta pelos direitos sociais, temendo os riscos de retrocessos, em função da observação de um desmonte das conquistas legais, sobretudo pela restrição de recursos (BRASIL, 2016). 
De todo modo, em meio a uma conjuntura de "conquistas em riscos" (ANPED, 2016), aos objetivos quantitativos ligados à expansão da EI associam-se reflexões sobre a necessidade de qualificar o atendimento (BRASIL, 2009a), enfatizando sua função pedagógica e, com isso, também a docência nesse campo ${ }^{1}$ (BRASIL, 2009b, 2009c). No que se refere à docência, as reflexões abarcam a complexidade do trabalho com crianças pequenas, a configuração e a (des)valorização dos quadros profissionais, os processos de formação inicial e continuada, entre outros temas ligados ao propósito de avançar na qualidade da educação.

Circunscrevendo as políticas públicas de formação, assinalamos que os Indicadores de Qualidade (BRASIL, 2009d) apontam a importância da formação docente. Nesse sentido, o Plano Nacional de Formação de Professores da Educação Básica (BRASIL, 2009c), previsto no Plano de Desenvolvimento da Educação (BRASIL, 2008), indica a formação inicial, a complementação da formação inicial (para docentes que ainda não concluíram a graduação) e a promoção de cursos de pós-graduação. Nesse contexto, tomamos a mobilização pela garantia do direito à EI considerando, em especial, o movimento de qualificação dos quadros profissionais, encaminhado com a promoção de cursos de pós-graduação lato sensu. Desenvolvemos pesquisa acompanhando a experiência em um curso de especialização em docência na EI, realizado em uma universidade federal da Região Sudeste do Brasil, em parceria com a Secretaria de Educação Básica (SEB) do Ministério da Educação (MEC).

Buscamos esse contexto para tematizar o trabalho docente em articulação com o direito à formação, focalizando as trajetórias formativas e de atuação das professoras cursistas. $\mathrm{O}$ estudo, realizado por meio de abordagem qualitativa exploratória, contou com 36 professoras (atuantes em instituições públicas de municípios da região metropolitana local), em sua maioria efetivas, que podem ser incluídas na categoria de profissionais experientes, ${ }^{2}$ com uma média de dez anos de carreira. Em sua totalidade do gênero feminino, informaram idades variando entre 29 e 51 anos. Com referenciais bakhtinianos (BAKHTIN, 2003, 2010), dialogamos com os dizeres das professoras nas relações tênues entre singularidade e universalidade, compreendendo que as contrapalavras informam assinaturas, marcando a participação ativa nas discussões para as quais foram chamadas a participar. $\mathrm{Na}$ atenção às relações dialógicas, os procedimentos reuniram a produção de memoriais sobre trajetórias de formação, a aplicação de questionário sobre o desenvolvimento da docência na EI e a discussão de dados (decorrentes do questionário) em grupo focal com o coletivo do grupo. ${ }^{3}$

A partir dos dados produzidos, organizamos três eixos de análises: no primeiro, abordamos o tema docência, considerando as condições de trabalho e de emprego em vinculação com a satisfação na profissão; no segundo, exploramos as motivações para a atuação, as características e os desafios enfrentados; no terceiro, abordamos alguns indicadores referentes às práticas pedagógicas no contexto dos encontros com as crianças. Com isso, abarcamos um conjunto de reflexões sustentadas num quadro ampliado de referenciais presentes em cada eixo de análise. Essas referências foram articuladas sob um arcabouço bakhtiniano, com vistas a marcar que a docência se desenvolve numa dialogia ampliada, envolvendo as crianças com suas necessidades e contribuições, as famílias com suas

\footnotetext{
${ }^{1}$ Sempre que nos referirmos à docência na EI, adotamos o gênero feminino, devido à reconhecida predominância de mulheres nessa etapa da educação básica.

${ }^{2}$ De acordo com as fases de desenvolvimento da carreira previstas por Huberman (2007), professores com mais de cinco anos de carreira podem ser incluídos na categoria de profissionais experientes.

${ }^{3}$ Registramos nosso agradecimento ao coletivo do Grupo de Pesquisa Formação e Atuação de Educadores (Grufae) - integrado por um grupo de estudantes de pós-graduação e de graduação vinculados ao Programa de Educação Tutorial: Projeto Educação (Petedu) -, que se constituiu parceiro no desenvolvimento dos procedimentos de produção de dados na pesquisa.
}

Revista Educação e Fronteiras On-Line, Dourados/MS, v.8, n.23 p.21- 34, maio/ago. 2018 
expectativas e demandas, o magistério (pares) com suas reivindicações, os poderes públicos com suas normativas e políticas de execução, a produção acadêmica com suas análises e recomendações, os movimentos sociais com suas bandeiras de lutas etc.

Assim, o trabalho docente na EI se efetiva no encontro (não sem desencontros e confrontos) com muitos outros que, por variados caminhos, diferentes contatos e distintos dizeres, tomam esse contexto no endereçamento de suas assertivas, buscando (não sem tensões) circunscrever a configuração da EI e, consequentemente, a constituição da docência nesse campo. Nessa perspectiva, passamos ao primeiro eixo, voltado à abordagem das condições de trabalho, de emprego e de estabilidade na carreira, entendidos como elementos que, impactando a constituição da docência, assinalam indicadores nas reflexões sobre o direito à educação.

\section{Trabalho, emprego e carreira na educação infantil}

Os tópicos deste eixo informam desafios da docência no Brasil, evidenciados por condições precárias de trabalho e emprego, planos de carreira questionáveis ou inexistentes, salários incompatíveis com a relevância social da profissão e problemas nos processos de formação (CÔCO, 2012; KRAMER, 2005 e outros). Nesse panorama, partimos do princípio de que as condições de emprego - formas de contratação, remuneração, carreira e estabilidade estão diretamente relacionadas com as condições de trabalho e, por sua vez, estão ligadas à satisfação (OLIVEIRA; ASSUNÇÃO, 2010). No contexto da EI, objetivamos compor um quadro das condições de emprego, integrando elementos relativos à satisfação com a profissão.

Nesse propósito, o princípio dialógico bakhtiniano (BAKHTIN, 2003), como pressuposto teórico-metodológico, conduz-nos no encontro com as reflexões sobre o desenvolvimento profissional (GARCÍA, 1999) e com a perspectiva de ciclos profissionais (BOLIVAR, 2002; HUBERMAN, 2007 e outros). Nesse encontro, a articulação com a noção de alteridade (BAKHTIN, 2003) permite configurar uma compreensão de que os docentes se formam ao longo dos anos na e pela relação com os outros sujeitos, situados nas condições em que se desenvolvem os contextos de trabalho.

Com isso, aproximamo-nos da ideia de desenvolvimento profissional, considerando as aprendizagens docentes ao longo da trajetória, implicando a forma como o professor ensina, se relaciona, constitui suas práticas e se constitui como profissional (MARTINEZ, 2010). Assim, ele reúne os aprendizados no desenvolvimento das práticas educativas com as crianças e nas situações específicas destinadas à formação (cursos de especialização, palestras, grupos de discussão, estabelecimento de parcerias etc.), afirmando uma noção de desenvolvimento contextual - orientado a partir do conjunto de ações que integram as perspectivas do desenvolvimento pessoal, da formação inicial e continuada e também da busca coletiva por melhorias nas instituições -, e não uma evolução linear e individualizada (GARCÍA, 1999). Desse modo, alguns aspectos podem prejudicar o desenvolvimento profissional dos docentes, tais como:

[...] uma burocratização, proletarização e intensificação do trabalho dos professores, que leva a um aumento do controle, uma diminuição da autonomia e capacidade de tomar decisões, um aumento significativo de tarefas a realizar ao mesmo tempo e com escassos incentivos ao longo de sua carreira docente [...] (GARCÍA, 1999, p. 145).

Nessa problematização, situamos nossas análises na especificidade da EI (BRASIL, 2009d, 2009e), partindo da premissa de que os indivíduos se constituem na relação de alteridade 
(BAKHTIN, 2003), de modo a assinalar o desenvolvimento da docência em intensas relações, reunindo vivências que (re)posicionam as visões sobre a atuação e os modos de fazer. Nesse sentido, para compor esse eixo, destacamos dados referentes aos vínculos de emprego (integrando renda, função e plano de carreira) e aos aspectos gerais do exercício profissional (considerando satisfação, estabilidade e sentimentos de cobrança e de valorização etc.).

As condições de trabalho envolvem diversos elementos, abarcando desde as instalações físicas das instituições e materiais até as formas de contratação, remuneração, carreira e estabilidade, designadas por relações de emprego. Tais condições influenciam o bem-estar dos trabalhadores e as suas aprendizagens, afetando tanto seu cotidiano profissional quanto sua vida pessoal (OLIVEIRA, 2008). Considerando esses elementos, no contexto das professoras que participaram da pesquisa, os vínculos de emprego são, em sua maioria, estatutários (97\%); consequentemente, suas carreiras estão inseridas em Planos de Cargos e Salários do Magistério. Quanto à renda individual mensal decorrente desse vínculo, destacamos a presença de rendimento acima do piso salarial ${ }^{4}$ ainda que um grupo significativo de professoras não esteja na faixa de valores superiores ao piso. Apuramos uma distribuição que abarca as faixas de 1 a 2 salários mínimos (SMs) (22,2\%), de 3 a 4 SMs (47,2\%), de 5 a 6 SMs, $(8,3 \%)$ e de 7 a 8 SMs $(19,4 \%)$. Nesses indicadores, cabe considerar que um quantitativo significativo das professoras (47\%) se apresenta como principal provedor de renda da casa.

A análise dos valores salariais implica considerar os requisitos de formação (em curso superior, tendo, em muitos casos, uma pós-graduação anterior à especialização em curso), a presença de progressão em função de titulação, tempo de serviço e atualização e/ou aperfeiçoamento $^{5}$ e, quando pertinente, a assunção de funções gratificadas. ${ }^{6}$ As correlações entre remuneração, formação e tempo de serviço permitem inferir que o ingresso na carreira estatutária (agregando estabilidade e inserção em planos de cargos e salários) incide no aumento progressivo dos salários, evidenciando a importância dos planos de carreira. Na análise, desses indicadores, cabe realçar a configuração do grupo pesquisado (de professoras), uma vez que estudos mostram indicadores muitos diferentes quando se toma o conjunto dos profissionais atuantes na EI, já que esse campo vem integrando professores e profissionais auxiliares (em condições muito distintas em relação a requisitos de formação, vínculo funcional e condições de reconhecimento e valorização) na atuação direta com as crianças (FERREIRA; OLIVEIRA; VIEIRA, 2012, CÔCO, 2015 e outros).

Em uma síntese das condições de trabalho (somando os indicadores sempre e frequentemente), apuramos que as professoras observam melhorias (61\%) e se sentem satisfeitas com a carreira (86\%) e com a remuneração (69\%). Todavia, uma análise detalhada desses dados em cotejamento com outras categorias (com equivalência nas exigências de formação) permite assinalar que os professores, de modo geral, não gozam de indicadores de reconhecimento em condições igualitárias com outras categorias profissionais. Numa visão geral sobre a docência, é possível observar regulações que, para um quantitativo ampliado da categoria, têm resultado em "[...] significativa intensificação do trabalho e precarização das relações de emprego, em mudanças que repercutem sobre a identidade e profissão docente" (OLIVEIRA, 2008, p. 30).

\footnotetext{
${ }^{4}$ No ano de realização da pesquisa, o piso salarial correspondia à aproximadamente dois salários mínimos.

${ }^{5}$ Quanto aos indicadores de tempo de serviço em rede pública, o grupo pesquisado estava distribuído nas faixas de 1 a 5 anos (13,8\%), 6 a 10 anos (36,2\%), 11 a 20 anos (41,7\%), 21 a 30 anos (5,5\%) e mais de 30 anos $(2,8 \%)$. A temporalidade na carreira se mostrou como indicador de forte vinculação com a remuneração, uma vez que a experiência tem sido o elemento mais comum de progressão dos planos de cargos e salários.

${ }^{6}$ No grupo, apuramos dois casos de professoras que prestaram concurso público para a função de professor e, no momento da pesquisa, atuavam em função (com acréscimo de gratificação) de gestão de instituição educativa.

Revista Educação e Fronteiras On-Line, Dourados/MS, v.8, n.23 p.21- 34, maio/ago. 201825
} 
Avançando para integrar, nesse eixo, outros indicadores que dialogam com a questão da satisfação profissional, destacamos também que apuramos altos índices de afinidade (91\%) e satisfação (83\%) com o trabalho que realizam, de busca de meios para melhorar a atuação (91\%) e de participação em atividades de formação promovidas pela instituição e pelas Secretarias de Educação (94\%). $\mathrm{Na}$ análise desses indicadores, cabe observar que diferentes estudos evidenciam dificuldades nas condições de trabalho e emprego na EI. Então, também no destaque das particularidades do grupo pesquisado, cabe realçar que os dados aqui explorados representam as vivências de um grupo experiente, em pleno desenvolvimento da carreira, apresentando graus de estabilidade que geralmente não se encontram nas fases mais iniciais da atuação (ZUCOLOTTO; CÔCO, 2015).

Estudos sobre ciclos profissionais indicam distintos momentos na carreira docente, de modo que as concepções e percepções podem mudar de acordo com as experiências acumuladas, também favorecendo o desenvolvimento de maior autonomia, segurança e engajamento na busca por melhorias (BOLÍVAR, 2002; HUBERMAN, 2007). Nessa perspectiva, cabe enfatizar a especificidade do trabalho docente na EI, distinto por diversos aspectos: por envolver crianças pequenas, pela estreita relação com as famílias, por requerer a organização dos conhecimentos visando ao desenvolvimento integral das crianças, entre outros (BRASIL, 2009a). Esses são aspectos que demonstram intensas relações, com um conjunto ampliado de interlocutores, que informam expectativas e cobranças, instando sistematicamente o desenvolvimento da docência nesse campo.

Nesse sentido, apuramos o reconhecimento das professoras (somando os indicadores sempre e frequentemente) quanto às cobranças de si mesmas $(88,9 \%)$, dos pais $(50 \%)$, da Secretaria de Educação (50\%), da direção da instituição (38,9\%), da supervisão pedagógica da instituição $(33,3 \%)$ e dos colegas $(25 \%)$. Nesse quadro de percepção sobre avaliação, em que os interlocutores externos (Secretaria e familiares das crianças) aparecem com maior destaque do que os internos (direção, supervisão, pares e crianças), sugerimos que, com o passar dos anos de profissão, o reconhecimento da experiência pode implicar maior segurança, ecoando na percepção do recebimento de menos cobranças decorrentes do ambiente das instituições. Diferentemente, pesquisas com iniciantes na EI vêm informando que frequentemente eles têm a sensação de cobrança dos parceiros mais próximos (ZUCOLOTTO; CÔCO, 2015). De todo modo, o destaque maior é para as cobranças de si mesmos, reiterando dados das pesquisas que têm assinalado os docentes como profissionais críticos do seu próprio trabalho (FERREIRA; OLIVEIRA; VIEIRA, 2012).

Marcelo García (1999) assinala a vinculação do desenvolvimento profissional com os processos de avaliação, alertando para os riscos da repressão à autonomia e às propostas de inovação das práticas. Na perspectiva de afirmação da autonomia docente (somando os indicadores de sempre e frequentemente), os dados indicam que as professoras consideram que exercem controle sobre a seleção do conteúdo, a escolha do material didático, os modos de educar e a avaliação das crianças (78\%). No contexto de um trabalho que se desenvolve ao longo da carreira, nele implicada a formação, atentamos para a reflexão de que a aquisição de segurança e estabilidade não anula a necessidade de atenção aos desafios da EI, em função de sua trajetória de consolidação, agregando novos requisitos para as ações educativas, em especial, voltadas ao reconhecimento da centralidade das crianças (BRASIL, 2009a, 2009b, 2009d, 2009e).

Assim, concluindo este tópico, destacamos que, não desconsiderando os processos de precarização do trabalho docente que afetam o conjunto da educação, cabe assinalar que esses processos podem se manifestar com distinções, observando contextos e grupos profissionais. Com isso, nossa pesquisa marca as especificidades desse grupo de professoras que se encontram Revista Educação e Fronteiras On-Line, Dourados/MS, v.8, n.23 p.21-34, maio/ago. 201826 
em um ciclo profissional considerado experiente (portanto, com estabilidade na carreira) e que atuam numa região metropolitana. Evidenciando esse quadro, passamos a explorar o segundo eixo, referente às motivações, às características e aos desafios enfrentados.

\section{Motivações, características e desafios na docência na Educação Infantil}

Neste eixo, os tópicos abarcam questões vinculadas às relações entre teoria e prática, às mudanças legais e conceituais, a novas análises das condições de trabalho e ao desenvolvimento da formação, entre outros temas. Nesse contexto, os indicadores de formação mostram que a maior parte do grupo pesquisado concluiu o curso superior (formação inicial) nos últimos seis anos (antes do ingresso na Especialização, em 2012), com a peculiaridade de indicador de presença de um primeiro curso de Especialização concluído (72,2\%). A análise detalhada desse indicador informa que a primeira Especialização, ainda que vinculada à área educacional, não indica aproximações com a EI, justificando a busca pela segunda Especialização. Nesse aspecto, marca-se a busca por conhecimentos aproximados do exercício profissional, permitindo considerar o reconhecimento da formação na sua qualificação.

Partindo desse reconhecimento, abordamos dois indicativos apurados nos dados. O primeiro assinala a possibilidade de circunscrever características relacionadas com o exercício da docência, indagando referências a elementos como amor, paciência e afeto por crianças. $\mathrm{O}$ segundo indicativo assinala a demanda por processos de formação, aliados à conquista de melhorias nas condições de atuação. Esses indicativos acenam tensões no campo profissional que não se apartam da observação do conjunto da vida das professoras. Nas diferentes jornadas (de mãe, filha, esposa, professora...), emerge uma integração de conhecimentos decorrentes de aprendizagens situadas em distintos contextos, envolvendo também acúmulos de tarefas e desgastes, observando a posição da mulher na sociedade e na cultura e a trajetória feminina na docência, em especial na EI (ARAGÃO; KREUTZ, 2010).

A constatação da intensificação do trabalho docente (DUARTE, 2010) motiva a indagar a possibilidade de organização de espaços/tempos formativos articulados com a promoção de melhores condições ao exercício profissional. Os indicadores de dificuldades apurados na pesquisa apontam para a necessidade de (re)organização dos espaços (requerendo melhorias na infraestrutura e na disponibilidade de materiais), de garantias de planejamento, de estímulos aos estudos coletivos, de fomento à sistematização e registro, assim como de fortalecimento do reconhecimento social da docência (em especial, na abordagem das relações entre a escola e as famílias). Esse quadro informa novos indicativos aos elementos tratados no primeiro eixo, permitindo considerar que o grupo pesquisado assinala um reconhecimento de conquistas sem, com isso, invisibilizar os desafios persistentes, de modo a evidenciar que precisamos agregar novas conquistas, possibilitando avançar o patamar avaliativo nas análises da trajetória da EI. Nessa complexidade, passamos a tratar das motivações e características da docência.

No conjunto dos dados, ao analisarmos as questões associadas às características para atuar na EI, notamos uma composição profissional agregadora de muitos elementos. Recortando as características mais elencadas, é possível reunir atributos referentes a compromisso, responsabilidade, afeto por criança, amorosidade, carinho, paciência, flexibilidade, atenção, dinamicidade, criatividade e predisposição ao estudo. Esses indicadores, situados no contexto da história de constituição da EI, associam questões de âmbito pessoal às que envolvem formação específica, numa complexidade que aproxima o envolvimento emocional e o compromisso político (KRAMER, 2005). Entre as motivações que conduziram as professoras à atuação, três ideias foram recorrentes: o afeto por crianças, a emergência de 
uma oportunidade profissional e, nesta, a vinculação com a metodologia de trabalho requerida na EI.

A expressão "gostar de criança", associada a amor e carinho, apontada como motivação para a atuação na EI e (re)afirmada como característica necessária, em uma primeira análise, parece naturalizar o "gostar de criança" como característica necessária e, em alguns momentos, suficiente à docência na EI. Cabe lembrar uma influência, já evidenciada em pesquisas, da concepção de que, para ser "educadora", bastava ser mulher, apresentar habilidades maternas e gostar de crianças (VIEIRA; SOUZA, 2010), de modo a observar a associação com lógicas ligadas à missão e/ou à paixão, no sentido também de envolvimento pessoal (NASCIMENTO et al., 2005). Mesmo com a inclusão da EI na Educação Básica (BRASIL, 1996) e a instituição das Diretrizes Curriculares (BRASIL, 2009a), ainda parecem ser fortes as concepções que sustentaram sua expansão no Brasil por meio da força de trabalho de professoras leigas e mulheres das classes populares (ROSEMBERG, 1999).

Na problematização dessas condições, a consciência política e a formação podem se constituir como mecanismo de desnaturalização de lógicas implicadas com a doação. Esse processo vem marcando as mobilizações das organizações sindicais e dos movimentos sociais. No quadro de nossa pesquisa, apuramos dados reduzidos de filiação sindical (30\%) e de participação em movimentos sociais (16\%). De todo modo, nos tensionamentos envolvendo distintas compreensões do trabalho na EI, evidenciamos, também, a partir dos dados decorrentes das questões abertas do questionário, ${ }^{7}$ motivações fomentadas com o processo de expansão, oferecendo oportunidades de ingresso nesse campo:

[...] $\mathrm{Na}$ época, eu era formada em magistério e a creche precisava de um professor. Fui admitida na prefeitura e passei a gostar de trabalhar com crianças de zero a seis anos [...] (PI 9).

Inaugurou perto de minha residência uma UMEI, fui visitar e me identifiquei rapidamente com a área [...] (PI 10).

Destarte, temos um conjunto de problematizações que podem ser dirigidas também à formação e, consequentemente, à análise das carreiras, chamando a atenção para a atratividade da educação (GATTI et al., 2010), para considerar a possibilidade de gerar pertencimento (CÔCO, 2012). Nesse pertencimento, a formação pode se constituir como um instrumento de valorização do trabalho, possibilitando aproximar os sentidos carreados pela identificação com as crianças e/ou pela oportunidade profissional dos conhecimentos específicos da área, contribuindo no fortalecimento da qualidade da EI.

$\mathrm{Na}$ análise dos dados referentes aos desafios, de partida, cabe salientar a observação de um intento de ação, desejo de fazer e de investir, demarcando o engajamento. Na descrição desse empenho, alguns aspectos foram recorrentes, evidenciando disputas entre concepções e reiterando a busca por melhorias nas condições:

O maior desafio é afirmar sua real importância na formação das crianças, já que, infelizmente, ainda é vista como um espaço de cuidados. O desafio é defender, sempre que necessário, a necessidade da EI e conscientizar a família sobre sua participação no ambiente escolar (PI 8).

Os desafios são imensos... Mas tentar romper com os aspectos assistencialistas da EI tem sido marcante. É preciso que a sociedade deixe de ver as professoras de EI como

\footnotetext{
${ }^{7}$ Para a organização e análise dos dados decorrentes do questionário, codificamos os instrumentos (utilizando a letra inicial da categoria profissional seguida de um número, ou seja: P1, P2, P3 e assim sucessivamente), com vistas a proteger a identidade das professoras.
}

Revista Educação e Fronteiras On-Line, Dourados/MS, v.8, n.23 p.21- 34, maio/ago. 2018 
babás e as vejam como profissionais competentes que amam as crianças e desejam fazer o melhor para elas (PI 24).

Na multiplicidade de elementos que constituem as condições de trabalho (OLIVEIRA; ASSUNÇÃO, 2010), observamos um quantitativo significativo de respondentes da pesquisa (35\%) que destacam os desafios ainda persistentes na EI. Como exemplo:

\begin{abstract}
As salas muito cheias, material pedagógico pouco ou inadequado, desvalorização do professor (baixos salários, sobrecarga de trabalho por necessitar atuar em dois ou até três horários, adoecimento). As políticas públicas que não atendem à demanda educacional (faltam escolas, os professores têm pouco preparo, os espaços são inadequados ou até mesmo sem uso...) (PI 1).
\end{abstract}

Pesquisas têm problematizado as condições de trabalho na EI ao tratar da qualidade (CAMPOS, 1994; OLIVEIRA; ASSUNÇÃO, 2010; DUARTE, 2010; CÔCO, 2012). Nesse quadro, assinalamos um cenário multifacetado da profissão que se reinventa na complexidade de viver uma trajetória de luta que tem ecoado em algumas conquistas, em meio a desafios persistentes, no horizonte de qualificar, cada vez mais, os atributos de garantia do direito à educação das crianças pequenas (CÔCO, 2015). Nesse sentido, realçamos desafios à promoção do desenvolvimento integral das crianças, requerendo que os profissionais da educação tenham formação, condições adequadas, reconhecimento e valorização, com vistas a responder às normativas preconizadas para as práticas pedagógicas, temário explorado no próximo eixo.

\title{
Proposições nas práticas pedagógicas para a Educação Infantil
}

Conforme viemos encaminhando, é importante considerar que a formação articulada à singularidade da docência se mostra como elemento-chave para o desenvolvimento profissional e para a afirmação dos campos de trabalho, tornando-se fundamental na qualificação das práticas profissionais, com vistas à garantia do direito à educação. Nessas interfaces, as práticas profissionais dialogam com as normativas e com as condições contextuais de cada instituição educativa. Na EI, o espaço coletivo institucional assume uma importância significativa, na medida em que compartilha com a família o processo educativo das crianças. Nessa perspectiva, a docência, compreendida pelo viés da atuação interativa com as crianças, requer o investimento em um currículo que articule "[...] as experiências e os saberes das crianças com os conhecimentos que fazem parte do patrimônio cultural, artístico, ambiental, cientifico e tecnológico" (BRASIL, 2009a).

Considerando essa demanda, os dados da pesquisa assinalam que as condições estruturais impactam a proposição das práticas pedagógicas, afetando o conjunto do trabalho docente. Na observação do direito das crianças "[...] a um ambiente aconchegante, seguro e estimulante" (BRASIL, 2009c), foi possível apurar indicadores que permitem destacar o cuidado na proteção de acidentes (89\%), na oferta de salas limpas e ventiladas (65\%), na arrumação (60\%) e na busca de lugares adequados para o sono (41\%). Nesse contexto, procurase compor uma ambientação com exposição de registros de atividades encaminhadas com as crianças $(65 \%)$ e com relações cordiais entre a equipe (65\%). Ainda na categoria de ambientação, a abordagem do contato com a natureza (BRASIL, 2009a) possibilitou apurar indicadores de que sempre há o incentivo à observação e ao respeito aos animais (59\%) e o contato direto com o sol (45\%). Frequentemente, constata-se o investimento na observação e preservação da natureza $(51 \%)$, quando se possibilita à criança brincar com areia, argila,

Revista Educação e Fronteiras On-Line, Dourados/MS, v.8, n.23 p.21- 34, maio/ago. 201829 
pedrinhas, gravetos e outros elementos (47\%); olhar para fora através das janelas mais baixas e com vidros transparentes (30\%); e passear ao ar livre (19\%). De outro lado, raramente há a possibilidade de visitar parques, jardins e zoológicos (52\%) e de ter plantas e canteiros disponíveis (43\%).

Nos indicadores relativos ao direito das crianças ao movimento em espaços amplos (BRASIL, 2009d), o destaque permitiu compor uma gradação entre a supervisão dos adultos nas brincadeiras (65\%); a promoção da brincadeira em espaços externos (50\%); a organização, com as crianças, das brincadeiras aprendidas pelos professores quando eram pequenos (40\%); e a disponibilidade para brincar com as crianças (38\%).

$\mathrm{Na}$ observação das interações e brincadeiras como eixo da ação educativa, em vinculação com a luta por construir uma pedagogia própria (ROCHA, 1999), os variados dados sobre as proposições de práticas pedagógicas presentes na pesquisa permitem considerar, em síntese, que tanto os professores quanto as crianças estão imersos numa lógica diária de divisão de tempos, subordinada a uma sequenciação que demonstra o adultocentrismo reinante na eleição das vivências educativas. Nos encontros com as crianças, há de se considerar que as relações vêm colocando a infância numa posição subalterna em face à geração adulta. Com esses indicadores, é importante investir em considerar a especificidade da EI (distante de um modelo escolarizante), requerendo ainda contrapor-se à dicotomia corpo e mente instaurada em nossa sociedade. Urge, portanto, fundamentar as práticas em princípios de inteireza humana a fim de possibilitar a expressão infantil e adulta Nos desafios que se apresentam aos processos formativos, emerge a busca por garantir uma pedagogia com a infância, que tenha como preocupação as crianças, concebidas como seres humanos singulares, pertencentes a diferentes contextos sociais (AGOSTINHO, 2005).

Assim, como síntese, as questões tratadas nos três eixos não se apartam dos encaminhamentos relativos aos processos formativos e não se distanciam das discussões sobre as condições de trabalho e de reconhecimento profissional, indicando que a docência na EI envolve uma complexidade de indicadores que impactam o processo educativo no horizonte da discussão sobre a qualidade da educação.

\section{CONSIDERAÇÕES FINAIS}

$\mathrm{Na}$ abordagem do direito à educação, reconhecendo uma conjuntura de riscos aos direitos sociais, destacamos um conjunto de questões ligadas à EI, afirmando que a atuação docente e a formação se articulam e não podem ser apartadas das condições do campo de trabalho no contexto das disputas sociais pelos investimentos públicos.

A partir dos dados da pesquisa, assinalamos que o desenvolvimento profissional dos professores na EI integra uma trajetória de reconhecimento social da primeira etapa da educação básica, requerendo o fortalecimento dos investimentos em melhores condições de trabalho e de valorização docente, de infraestrutura e de materiais, com vistas a mover condições para problematizar - sistemática e ampliadamente para o conjunto dos profissionais - as concepções de crianças e de processos de cuidado e de educação, instando as práticas pedagógicas desenvolvidas. Nessa perspectiva, cabe salientar a interatividade constitutiva da docência na EI, tecida com permanentes diálogos que movem tensões, rupturas e transformações. Nas problemáticas emergentes, o espaço da formação se apresenta como um campo de possibilidades fomentadoras de novas iniciativas de ação. Se esse é um espaço de possibilidades - e isso queremos destacar -, a esse espaço não podem ser remetidas todas as demandas da EI. 
Assim, propondo uma responsabilização ampliada (que recusa a culpabilização dos professores), reiteramos que a afirmação da EI, como primeira etapa da educação básica, envolve um conjunto de elementos que abarcam demandas por investimentos em questões estruturais e por reconhecimento e valorização dos trabalhadores docentes, sustentadas por processos formativos que valorizem esse campo profissional.

Em síntese, não desconsiderando uma conjuntura de ofensivas às conquistas sociais, temos um quadro que evidencia a necessidade de continuar - e fortalecer - a luta histórica pelo direito à educação no contexto dos investimentos por qualificar as ações educativas.

\section{REFERÊNCIAS}

AGOSTINHO, Kátia Adair. A. Creche e pré-escola é lugar de criança. In: MARTINS FILHO, Altino José (Org.). Criança pede respeito: temas em educação infantil. Porto Alegre: Mediação, 2005. p. 63-73.

ASSOCIAÇÃO NACIONAL DE PÓS-GRADUAÇÃO E PESQUISA EM EDUCAÇÃO. (ANPED). Boletim, ano V, n. 20, maio 2016. Número especial "Conquistas em riscos". Disponível em: <http://www.anped.org.br/boletim/2015/975>. Acesso em: 8 set. 2017.

ARAGÃO Milena; KREUTZ, Lúcio. Do ambiente doméstico às salas de aula: novos espaços, velhas representações. Revista Conjectura, Caxias do Sul, v. 15, n. 3 p. 106-120, set./dez. 2010. Disponível em: <http://www.ucs.br/etc/revistas/index.php/ conjectura/issue/view/50/showToç>. Acesso em: 8 jan. 2017.

Estética da criação verbal. 4. ed. São Paulo: Martins Fontes, 2003.

BAKHTIN, Mikhail. Para uma filosofia do ato-responsável. São Carlos, SP: Pedro \& João Editores, 2010.

BOLÍlVAR, Antônio. Profissão professor: o itinerário profissional e a formação da escola. Bauru, São Paulo: Edusc, 2002.

BRASIL. Decreto $n^{o}$. 6.755, de 29 de janeiro de 2009. Institui a Política Nacional de Formação de Profissionais do Magistério da Educação Básica. Brasília, Casa Civil, 2009b. Disponível em: <http://www.planalto.gov.br/ccivil_03/_ato2007-2010/2009/decreto/d6755.htm>. Acesso em: 7 nov. 2014.

BRASIL. Emenda Constitucional $n^{o}$. 95, de 15 de dezembro de 2016. Altera o ato das disposições constitucionais transitórias, para instituir o novo regime fiscal e dá outras providências.

Disponível em: 
<https://www.planalto.gov.br/ccivil_03/constituicao/Emendas/Emc/emc95.htm>. Acesso em: 21 set. 2017.

BRASIL. Lei de Diretrizes e bases da Educação Nacional. Lei Federal nº 9.394, 1996. Disponível em: <http://www.planalto.gov.br/ccivil_03/leis/19394.htm>. Acesso em: 13 fev. 2013.

BRASIL. Ministério da Educação. Câmara de Educação Básica. Resolução $n^{o}$. 5, de 17 de dezembro de 2009. Fixa as Diretrizes Curriculares Nacionais para a Educação Infantil. Brasília, 2009a. Disponível em: <http://portal.mec.gov.br/index.php? option=com_ docman\&task=doc_download\&gid=9769\&Itemid=>. Acesso em: 7 de nov. 2014.

BRASIL. Ministério da Educação. Câmara de Educação Básica. O Plano de Desenvolvimento da Educação: razões, princípios e programas. Brasília, 2008. Disponível em: <http://portal.mec.gov.br/ arquivos/livro/livro.pdf>. Acesso em: 7 nov. 2014.

BRASIL. Ministério da Educação. Secretaria de Educação Básica. Critérios para um atendimento em creches que respeite os direitos fundamentais das crianças. Brasília, 2009e. Disponível em: <http://portal.mec.gov.br/dmdocuments/direitosfundamentais. pdf>. Acesso em: 7 out. 2014.

BRASIL. Ministério da Educação. Secretaria de Educação Básica. Indicadores da qualidade na educação infantil. Brasília, 2009d. Disponível em: <http://portal.mec.gov.br/dmdocuments/indic_qualit_educ_infantil.pdf>. Acesso: 7 out. 2014.

BRASIL. Plano Nacional de Educação (PNE). Lei Federal no 13.005, de 25 junho de 2014. Disponível em: <http://www.planalto.gov.br/CCIVIL_03/_Ato2011-2014/2014/ Lei/L13005.htm>. Acesso em 7 out. 2014.

BRASIL. Resolução CNE/CEB $n^{o}$. 2, de 28 de maio de 2009. Fixa as Diretrizes Nacionais para os Planos de Carreira e Remuneração dos Profissionais do Magistério da Educação Básica Pública. Brasília, 2009c. Disponível em <http://portal.mec.gov.br/ dmdocuments/resolucao_cne_ceb002_2009.pdf >. Acesso em: 9 mar. 2016.

CAMPOS, Maria Malta. Educar e cuidar: questões sobre o perfil do profissional de educação infantil. In: BRASIL. Ministério da Educação. Por uma política de formação do profissional de educação infantil. Brasília: MEC/SEB, 1994.

CÔCO, Valdete. Docência na educação infantil: de quem estamos falando? Com quem estamos tratando? In: FLORES, Maria Luiza Rodrigues; ALBUQUERQUE, Simone Santos de (Org.). 
Implementação do proinfância no Rio Grande do Sul: perspectivas políticas e pedagógicas. Porto Alegre: Edipucrs, 2015. v. 1, p. 143-160. Disponível em: $<$ http://portal.mec.gov.br/index.php?option=com_docman\&view=download\&alias=36711 ebook-implementacao-proinfancia-rio-grande-do-sul-perspectivas-politicas-pedagpdf\&category_slug=marco-2016-pdf\&Itemid=30192>. Acesso em: 10 dez. 2016.

CÔCO, Valdete. Trabalhador docente na educação infantil no Espírito Santo. In: FERREIRA, Eliza Bartolozzi; OLIVEIRA, Dalila Andrade; VIEIRA, Lívia Fraga. O trabalho docente na educação básica: o Espírito Santo em questão. Belo Horizonte: Fino Traço, 2012. p. 59-80.

DUARTE, Adriana. Intensificação do trabalho docente. In: OLIVEIRA, Dalila Andrade; DUARTE, Adriana Maria Cancella; VIEIRA, Lívia Maria Fraga. Dicionário: trabalho, profissão e condição docente. Belo Horizonte: UFMG/Faculdade de Educação, 2010. 1 CDROM.

FERREIRA, Eliza Bartolozzi; OLIVEIRA, Dalila Andrade; VIEIRA, Lívia Fraga (Org.). $O$ trabalho docente na educação básica: a condição docente em sete Estados brasileiros. Belo Horizonte: Fino Traço, 2012.

GARCIA, Carlos Marcelo. Formação de professores: para uma mudança educativa. Porto, PT: Porto, 1999.

GATTI, Bernadete Angelina et al. A atratividade da carreira docente no Brasil. Estudos \& Pesquisas Educacionais, São Paulo: Fundação Carlos Chagas, n. 1, p.139-210, maio 2010. Disponível em <http://www.consed.org.br/media/download/54b662d720203.pdf>. Acesso em: 10 dez. 2016.

HUBERMAN, Michael. O ciclo de vida profissional dos professores. In: NÓVOA, Antônio. (Org.). Vida de professores. 2. ed. Porto, PT: Porto, 2007. p. 31-61.

KRAMER, Sônia (Org.). Profissionais da educação infantil: gestão e formação. São Paulo: Ática, 2005.

MARTINEZ, Javier Campos. Desenvolvimento profissional docente. In: OLIVEIRA, Dalila Andrade; DUARTE, Adriana Maria Cancella; VIEIRA, Lívia Maria Fraga. Dicionário: trabalho, profissão e condição docente. Belo Horizonte: UFMG/Faculdade de Educação, 2010. 1 CD-ROM. 
NASCIMENTO, Anelise et al. Nos relatos de professores, conquistas e ambiguidades da educação infantil. In: KRAMER, Sônia. (Org.). Profissionais de educação infantil: gestão e formação. São Paulo: Ática, 2005. p. 37-54.

OLIVEIRA, Dalila Andrade. O trabalho docente na América Latina: identidade e profissionalização. Revista Retratos da Escola, Brasília, v. 2, n. 2-3, p. 29-39, jan./dez. 2008. Disponível em: <http://www.esforce.org.br>. Acesso em: 12 jan. 2012.

OLIVEIRA, Dalila Andrade; ASSUNÇÃO, Ada Ávila. Condições de trabalho docente. In: OLIVEIRA, Dalila Andrade; DUARTE, Adriana Maria Cancella; VIEIRA, Lívia Maria Fraga. Dicionário: trabalho, profissão e condição docente. Belo Horizonte: UFMG/Faculdade de Educação, 2010. 1 CD-ROM.

ROCHA, Eloisa Acires Candal. A pesquisa em educação infantil no Brasil: trajetória recente e perspectivas de consolidação de uma pedagogia. Florianópolis: NUP, 1999.

ROSEMBERG, Fúlvia. Educar e cuidar como funções da educação infantil no Brasil: perspectiva histórica. São Paulo: Faculdade de Ciências Sociais, Pontifícia Universidade de Campinas, 1999.

VIEIRA, Lívia Fraga; SOUZA, Gisele. Trabalho e emprego na educação infantil no Brasil: segmentações e desigualdades. Educar em Revista, Curitiba, p. 119-139, 2010. Número especial. Disponível em: <http://ojs.c3sl.ufpr.br/ojs2/index.php/educar/ issue/view/1147/showToc>. Acesso em: 12 jan. 2012.

ZUCOLOTTO, Valeria Menassa; CÔCO, Valdete. Processos formativos de professoras iniciantes na educação infantil. Horizontes, Edusf, v. 33, p. 85-96, 2015. Disponível em: $<$ http://revistahorizontes.usf.edu.br/horizontes/issue/view/13/showToc $>$. Acesso em: 12 jan. 2012.

Recebido em: 11/02/2018

Aceito em: 05/04/2018 